\title{
Functional Form for Estimating the Lorenz Curve
}

\author{
Bijan Bidabad \\ B.A., M.Sc., Ph.D., Post-Doc. \\ Professor \\ Economics and Chief Islamic Banking Advisor \\ Bank Melli, Iran \\ E-mail:bijan@bidabad.com \\ Behrouz Bidabad \\ Faculty of Mathematics \\ Polytechnics University, Hafez Ave \\ Tehran, I59I4, Iran \\ E-mail:bidabad@aut.ac.ir
}

\begin{abstract}
A flexible Lorenz curve which offers different curvatures allowed by the theory of income distribution is introduced. The intrinsically autoregressive nature of the errors in cumulative data of the Lorenz curve is also under consideration.
\end{abstract}

Keywords: Lorenz Curve, Functional Form, Estimation, Income Inequality, Distribution

\section{Introduction}

Income distribution is often portrayed on a Lorenz curve. In recent years some of its functional forms have been introduced. These forms should satisfy some definitional properties, and also make estimation of the function parameters by the known estimating methods simple. This note emphasizes on two other characteristics of the Lorenz curve which have been neglected. First, the Lorenz curve could be non-symmetric with respect to the line $y=I-x$, for $0 \leq x \leq I$. This enables that different Lorenz curves cross the others which are the same in functional form and different in parameters for $0<_{x}<\mathrm{I}($ see E. E. Hagen $(2)$ ). Figure I shows this phenomenon by two different Lorenz curves of A and B.

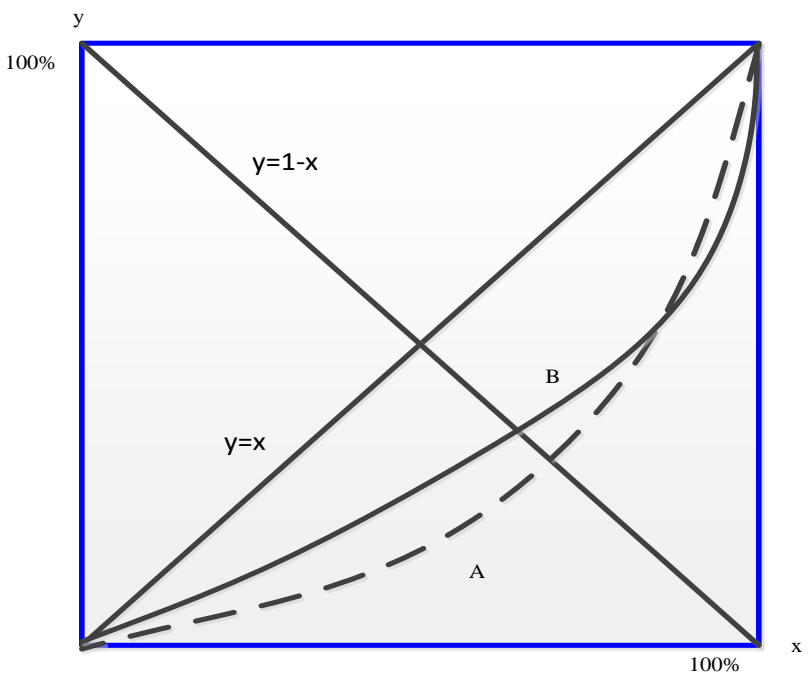

Figure I. 
M. R. Gupta (I) proposed the following definitional properties. The function $y=f(x)$ represents the Lorenz curve, if:

(i) $\mathrm{f}(0)=0$

(ii) $\mathrm{f}(\mathrm{I})=\mathrm{I}$

(iii) $f(x) \geq 0$ for $0 \leq x \leq I$

(iv) $\mathrm{f}^{\prime}(\mathrm{x}) \geq 0$ for $0 \leq \mathrm{x} \leq \mathrm{I}$

(v) $f(x) \leq x \quad$ for $\quad 0<x<$ I

(vi) $0 \leq \int_{0}^{1} f(x) \cdot d x \leq \frac{1}{2}$

It is obvious that (vi) is redundant; when (i) to (v) are satisfied. Because by manipulating (i) to (v) we have: $0 \leq f(x) \leq x$. By integrating this inequality, (vi) is derived:

$\int_{0}^{1} 0 d x \leq \int_{0}^{1} f(x) \cdot d x \leq \int_{0}^{1} x \cdot d x$

Or:

$0 \leq \int_{0}^{1} f(x) \cdot d x \leq \frac{1}{2}$

Therefore property (vi) is always satisfied, and we need no more to test (vi) for any function which satisfies (i) to (v).

Let's review the proposed functional forms:

Kakwani et al. (4):

$M=a \cdot N^{l}\left(2^{1 / 2}-N\right)^{c} \quad$ where $M=\frac{x-y}{2^{1 / 2}} ; \quad N=\frac{x-y}{2^{1 / 2}} ; \quad \mathrm{a} \geq 0 ; \quad 0 \leq 1 \leq \mathrm{I} ; \quad 0 \leq \mathrm{c} \leq \mathrm{I}$.

This form does not satisfy all the properties.

$\underline{\text { Rasche et al. (5): }}$

$y=\left[1-(1-x)^{a}\right]^{1 / l} \quad$ where $0 \leq \mathrm{a} \leq \mathrm{I} ; 0 \leq 1 \leq \mathrm{I}$.

This form makes the estimation of the parameters by the least squares method difficult.

\section{$\underline{\operatorname{Gupta}(\mathrm{I}):}$}

$y=x \cdot A^{x-1} \quad$ where $\mathrm{A}>\mathrm{I}$

This form satisfies definitional properties and simply can be estimated by ordinary least squares method; but by changing the parameter $A$ (from $A_{i}$ to $A_{i}$ ), the resulted functions $\left(y_{i}\right.$ and $\left.y_{i}\right)$ will never intersect for $0<_{x}<I$. To prove this, we can solve the following system: 
$\left\{\begin{array}{l}y=x \cdot A_{i}^{x-1} \\ y=x \cdot A_{j}^{x-1}\end{array}\right.$

Solutions are $x=y=0$ and $x=y=I$ which are not in the domain $0<x<I$.

\section{Proposition}

This note suggests the following functional form which satisfies the definitional properties (i) to (v); and by changing its parameters, the resulting curves may cross each other:

$y=x^{B} \cdot A^{x-1} \quad$ where $\quad \mathrm{B} \geq \mathrm{I} ; \quad \mathrm{A} \geq \mathrm{I} \quad$ for $0<\mathrm{x} \leq \mathrm{I}$

Definitional properties satisfy as follows:

(i) $f(0)=0$

(ii) $f(I)=I$

(iii) $\mathrm{f}(\mathrm{x})=x^{B-1} \cdot A^{x-1}(\mathrm{~B}+\mathrm{x} \cdot \log \mathrm{A})>0$ for $0<\mathrm{x}<\mathrm{I}$

(iv) $\mathrm{f}^{\prime}(\mathrm{x})=x^{B-2} \cdot A^{x-1}\left[(\mathrm{~B}+\mathrm{x} \cdot \log \mathrm{A})^{2}-\mathrm{B}\right] \geq 0$ for $0 \leq \mathrm{x} \leq \mathrm{I}$

(v) $\mathrm{f}(\mathrm{x})=x^{B} \cdot A^{x-1}=\frac{x^{B}}{A^{1-x}} \leq x \quad$ for $0<\mathrm{x}<\mathrm{I}$

Different shapes of the function as $y=x^{B_{i}} \cdot A_{i}^{x-1}$ and $\mathrm{y}=x^{B_{j}} \cdot A_{j}^{x-1}$ may have intersection for $0<\mathrm{x}<\mathrm{I}$. By solving the following system:

$\left\{\begin{array}{l}x^{B_{i}} \cdot A_{i}^{x-1} \\ x^{B_{j}} \cdot A_{j}^{x-1}\end{array}\right.$

We get:

$\frac{x-1}{\log x}=\frac{B_{j}-B_{i}}{\log \left(A_{i} / A j\right)}$

It is obvious when (2) is satisfied; there is an intersection between two curves of (I). So if we solve the following system

$\left\{\begin{array}{c}x-1=B_{j}-B_{i} \\ \log x=\log \left(A_{i} / A_{j}\right)\end{array}\right.$

We can find a relation in terms of $A_{i}, A_{j}, B_{i}$ and $B_{j}$ which satisfies (2). Therefore:

$A_{i} / A_{j}-1=B_{j}-B_{i}$

Hence, when $A_{i}, A_{j}, E_{i}$ and $B_{j}$ can satisfy equation (4), there is a solution (or intersection) for (I). But the intersection is inside the domain $0>\mathrm{x}>\mathrm{I}$ when:

By using (3) and (4) 
$\left\{\begin{array}{c}0<x=B_{j}-B_{i}+1<1 \\ 0<x=\left(A_{i} / A_{j}\right)<1\end{array}\right.$

Or:

$\left\{\begin{array}{c}0<B_{j}-B_{i}<1 \\ 0<A_{i}<A_{j}\end{array}\right.$

The second thing that has been ignored is the autoregressive nature of the errors in the Lorenz curve data. On the other hand, when there is an error in the $(t-1)^{\text {th }}$ percent of income earners, this error completely will transfer to the next cumulative percent $(t)$. This is because of using cumulative data to estimate the Lorenz curve. So if we define $u_{t}$ as disturbance term of the $\mathrm{t}^{\text {th }}$ observation (cumulative percent), autoregressive specification of the error would be:

$u_{t}=u_{t-1}+V_{t}$

with $V_{t}$ obeying classical assumptions of regression. Therefore the stochastic form of our suggested functional form could be as follow:

$y_{t}=x_{t}^{B} \cdot A^{x_{t}-1} \cdot e^{u_{t}}$

or:

$y_{t-1}=x_{t-1}^{B} \cdot A^{x_{t-1}-1} \cdot e^{u_{t-1}}$

Dividing (5) by (6) and taking natural logarithm:

$\log \left(\frac{y_{t}}{y_{t-1}}\right)=B \cdot \log \left(\frac{x_{t}}{x_{t-1}}\right)+\log A \cdot\left(x_{t}-x_{t-1}\right)+u_{t}-u_{t-1}$

Since $u_{t}-u_{t-1}=v_{t}$ and $\mathrm{E}\left(v_{t}, v_{t-1}\right)=0$ the problem $\mathrm{pf}$ autoregression has been discarded and (7) can be estimated by Ordinary Least Squares easily.

\section{References}

Gupta, M.R. "Functional Forms For Estimating the Lorenz Curve", Econometrica. 52(1984), I3I3-I3I4.

Hagen, E.E. "The Economics of Development". Richard D. Irwin, Inc. Homewood, Illinois. 1975, 21 6-2I7.

Kakwani, N.C. "Functional Form for Estimating the Lorenz Curve: A Reply". Econometrica, 48, (1980). I063-I064.

Kakwani, N.C.; N. Podder, "Efficient Estimation of the Lorenz Curve and Associated Inequality Measures from Grouped Observations." Econometrica. 44(1976), I37-I48.

Rasche, R.H., J. Gaffney, A.Y.C. Koo, Anan. Ofst: "Functional Forms for Estimating the Lorenz Curve," Econometrica, 48(1980), I06I-I062.

Bidabad, Bijan, Continuous LI norm estimation of Lorenz curve.

http://www.bidabad.com/doc/1I-articl4.pdf

Bidabad, Bijan, Estimating Lorenz curve for Iran by using continuous LI norm estimation, Economics and Management Journal, Islamic Azad University, No. 19, winter 1993, pp. 83-I0I.

http://www.bidabad.com/doc/iraninc-lI.pdf

Bidabad, Bijan, USA Income distribution counter-business-cyclical trend (Estimating Lorenz curve using continuous LI norm estimation). First meeting of the Society for the Study of Economic Inequality (ECINEQ), Palma de Mallorca, Spain, July 20-22, 2005.

http://www.uib.es/congres/ecopub/ecineq/general.html

http://www.uib.es/congres/ecopub/ecineq/papers/039Bidabab.pdf

http://www.bidabad.com/doc/estimating-lorenz-us.pdf 
Bidabad, Bijan, Hamid Shahrestani. An implied inequality index using LI norm estimation of Lorenz curve. Global Conference on Business and Finance Proceedings. Mercedes Jalbert, managing editor, ISSN I93I-0285 CD, ISSN I94I-9589 Online, Volume 3, Number 2, 2008, The Institute for Business and Finance Research, Ramada Plaza Herradura, San Jose, Costa Rica, May 28-3I, 2008, pp. I48-I63. Global Journal of Business Research, Vol. 4, No. I, 2010, pp.2945.

http://www.bidabad.com/doc/LI-Implied-inequality-index-4.pdf

http://www.theibfr.com/archive/ISSN-I94I-9589-V3-N2-2008.pdf

http://www.bidabad.com/doc/SSRN-idI63I86I.pdf

\section{Copyrights}

Copyright for this article is retained by the author(s), with first publication rights granted to the journal. This is an open-access article distributed under the terms and conditions of the Creative Commons Attribution license (http://creativecommons.org/licenses/by/4.0/). 